\title{
Power Quality Analysis of Wind Turbines. Part II - Dynamic Analysis
}

\author{
Joaquín Mur Ángel Antonio Bayod Samuel Ortiz Roberto Zapata
}

\begin{abstract}
This is the second part of a study on Power Quality (PQ) analysis of Wind Turbines (WT) installed in wind farms. A specifically designed measurement system has been installed in three wind farms with three different types of asynchronous generators of $600 \mathrm{~kW}$ and $700 \mathrm{~kW}$ classes.

This part is focused on the analysis of transient events, connections and disconnections and power fluctuations. A new method to study power fluctuations based in joint timefrequency analysis is proposed.

Transient events such as connection of capacitor banks are studied with the waveforms. The firing of thyristors during soft start is also studied through waveforms. The whole evolution during the connection of the generator is analyzed through the RMS value of each cycle of the grid because it is a longer transient. Power fluctuations are also studied through values of current and power each cycle or half-cycle.
\end{abstract}

Index Terms - wind energy, switching events, timefrequency analysis.

\section{INTRODUCTION}

The second part of the article deals with transitory events, as switching of generator at a WT. The overall effect of a switching event of a WT in a wind farm will be studied.

The switching events can be clearly noticed in the WT, but the effect in the substation of the park is quite weak. This is mainly due to the independent operation of the WT in a farm and the diverse wind conditions that each WT experiences. So, if switching events are fast enough, there is low probability that more than two turbines are connecting their generators at the same time.

Power fluctuations due to tower shadow and wind shear are studied through the frequency analysis. The power and the current present slow fluctuations (the spectrum quickly decreases from $2 \mathrm{~Hz}$ onwards). The fluctuations do not have a narrow frequency margin; they are spread in wide frequency bands. This fact may indicate that the fluctuations slowly vary their frequency, probably because the randomness of the wind acts desynchronizing and varying slightly the frequency of the turbines.

The periodogram (module averaged Power Spectrum Density) has proved suitable to remove noise and, at the same time, to maintain the content of the PSD.

There is a small probability that a turbine enters in a resonance or that the blades of some turbines pass in front of the tower synchronized. A time-frequency analysis has been

The authors are with CIRCE Foundation and the Electrical Engineering Department of Zaragoza University, Spain, (Tfn 349767619 20, Fax 34 9767622 26, e-mail: joako@posta.unizar.es).

The authors thank CEASA (Compañía Eólica Aragonesa S.A.) and TAIM-NEG-MICON by their essential support for this work. This work was also supported in part by Department of Education and Culture of Aragón (B134/98 grant).

The authors also thank Daniel Romanos, Roberto Sierra and Nacho Palacios for their contributions to the measurement system and for helping carrying out the installation of the system in the wind farms. performed to detect a possible resonance. Some methods with large time-frequency resolution as Wigner-Ville Distribution (WVD) and S-Method (SM) have been tested, but they generate cross-terms because of the wide range of frequencies in the signal. Therefore, the method less influenced by cross-terms and more stable is the Short Fast Fourier Transform (SFFT). In the SFFT, the Fourier Transform is applied to a small window of the signal. If a frequency appears remarkably perceptible in the correlogram, an eventual resonance of that frequency has happened during that elapse.

\section{DYNAMIC ANALYSIS}

Power injected to the grid by a wind farm shows fluctuations that are difficult to predict, even if data from a meteorological tower are available. Measurements form an anemometer and from a wind vane are local, and wind parameters vary with height from ground and along the farm, due to local orography and proximity of flow obstacles.

For example, the blades of a $750 \mathrm{~kW}$ turbine sweep a surface of around $1700 \mathrm{~m}^{2}$ and the differences in speed within are considerable. The origin of those variations is wind shear, tower shadow, wake of other turbines or near flow obstacles and atmospheric turbulence [1]. Some authors $[2,3]$ remark the tower shadow as the main effect. Kaimal spectrum [4] accounts for cyclic variations of the wind, separating variations owing to atmospheric turbulence and owing to micro clime and meteorological evolution.

If we consider that a wind farm can contain up to one hundred WT, the estimation of fluctuations at wind farm is quite complex. It requires large amount of data, exhaustive knowledge of the dynamics and the control of the WT and, in second place, of the characteristics of the grid.

Some authors consider that power fluctuations not produced by meteorological evolution can be modeled as independent statistical distributions. While power of a wind farm is the sum of the power of each turbine, short-time fluctuations at wind farm is the sum of several (independent) statistical distributions, where there is some degree of cancellation (power is proportional to $\mathrm{N}$, the number of turbines in a wind farm, but fluctuations are proportional to $\sqrt{ } \mathrm{N}$ if they are uncorrelated) [5]. Other authors consider some gusts as a wave front that travels at wind speed and arrives at the WT at different time lags [6]. The worst condition would result of wind reaching all the WT at the same time, giving the maximum expected power fluctuation.

Up to now, the only way to get realistic data of power fluctuations is to measure them. Standard IEC 61400-21 accounts for fluctuations from 6 to $25 \mathrm{~Hz}$ and switching events, which are significant to flicker. furthermore, power variations owing to diurnal cycle and meteorological evolution are much slower. Theses variations are important for load dispatch and they are related to predictability and weather forecast $[7,8]$. 


\section{A. TRANSIENT EVENTS.}

\section{A.1 Thyristor soft start (connection of generator)}

Fig. 1 shows current when the generator is gradually connected to the grid through thyristors with increasing conduction angle. The current is lagged practically half cycle. In the analyzed SQIG (Squirrel Cage Induction Generator), the initial conduction angle is about $90^{\circ}$ whereas the other WT start at $0^{\circ}$. The current is very reactive and the active component is negligible during connection. This causes a voltage sag due to the reactive nature of the shot-circuit impedance at the low voltage (LV) side of the WT (see Fig. 3 ). The distortion of current also affects slightly to the (phase-to-neutral) voltage waveform.

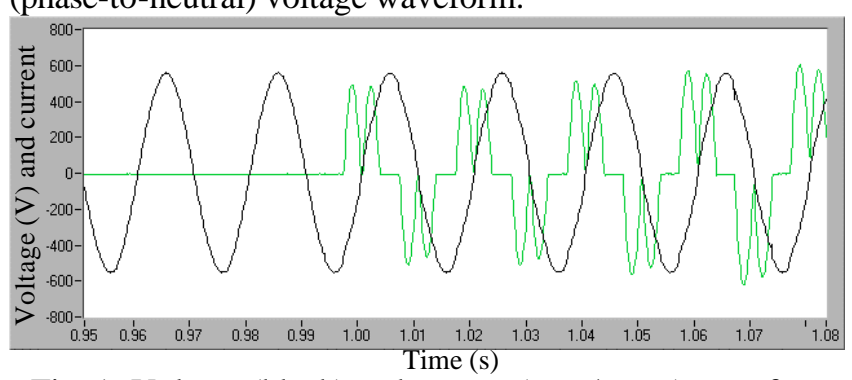

Fig. 1: Voltage (black) and current (grey/green) waveform during the connection of SQIG through thyristor soft start.

In Fig. 2, the intensity of current is shown during the connection. The conduction angle is increased from an initial value up to $180^{\circ}$, then the contactor that short-circuit thyristor is closed about $1 / 2$ or 1 second after the start (depending on the WT). At that moment, the slip of a SQIG is small and the generator continues accelerating for a while, until the equilibrium between the mechanical torque from the turbine and the electrical torque of the generator is reached. During connection, inrush current can reach the double of nominal value in SQIG with fixed blades.

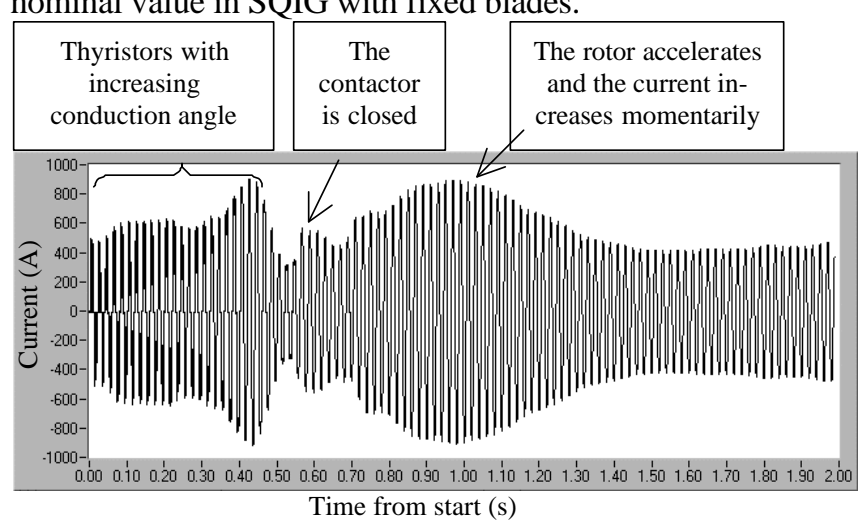

Fig. 2: Intensity of current during the connection of SQIG.

In fixed blade and constant speed turbines, the connection occurs at the instant when the turbine revolves at the appropriate speed. If generator speed were not optimal, this would lead to over-currents.

In contrast, the inrush current of generators with pitch control and VRIG (Variable Resistance Induction Generator) or DFIG (Doubly Fed Induction Generator) do not produce over-currents. The speed of the generator is controlled with the blade pitch, so the connection is made at the most favorable speed.

In VRIG, the inrush connection is about half the nominal in normal conditions. The control of apparent resistance of rotor helps to lower the inrush current. The reactive current due to the magnetizing current of the generator gets compensated when all the capacitors are connected.

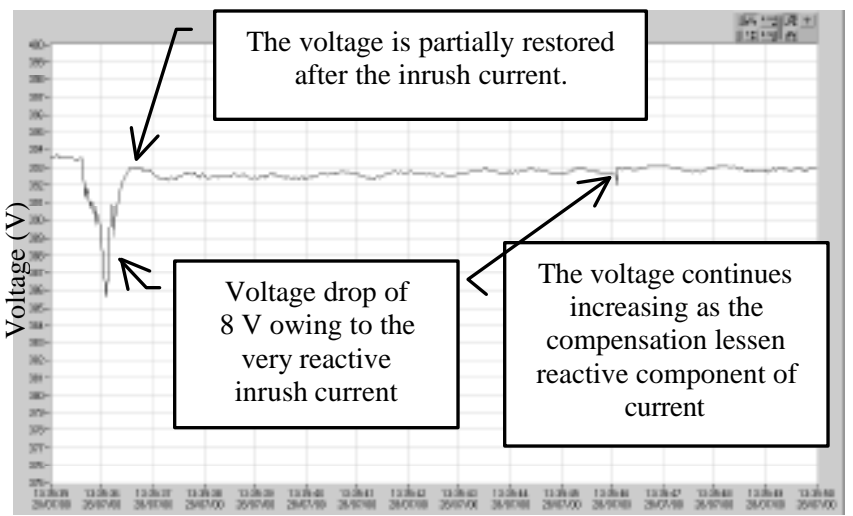

Fig. 3: RMS Voltage during the connection of SQIG (RMS phase to neutral voltage).

The softest connection is in VRIG, since the generator and blade control achieve a very low inrush current. The magnetization of the generator is achieved by the rotor currents injected through the slip rings. The IGBT converter provides the magnetizing current without reactive consumption from the grid.

In the WT analyzed, the process of connection in SQIG last $30 \mathrm{~s}$ (from soft-start till all capacitors are connected); VRIG lasts $7 \mathrm{~s}$ and DFIG lasts less than $1 \mathrm{~s}$. These timing can vary from one manufacturer to another.

\section{A.2 Disconnection of generator}

The disconnection also generates small voltage sags, since the capacitor bank is disconnected before the generator to avoid self-excitation. In Fig. 4, VRIG is softly disconnected reducing the conduction angle of the thyristors.

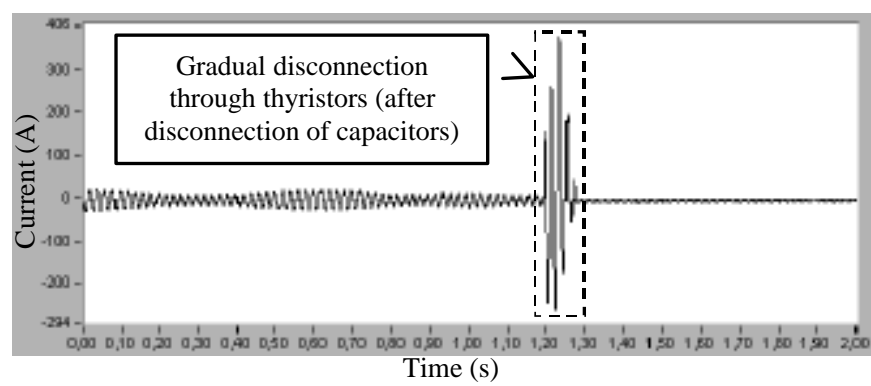

Fig. 4: Current waveform at VRIG during a disconnection.

In the DFIG, the electronic converter is disconnected before the generator. In this turbine, the generator is directly disconnected simply opening the contactor of the generator (the soft-start thyristors are not used during disconnection). Fig. 5 shows this small sag due to the reactive disconnection current that is only noticeable at the low voltage winding of the transformer (around $5 \%$ of voltage drop).

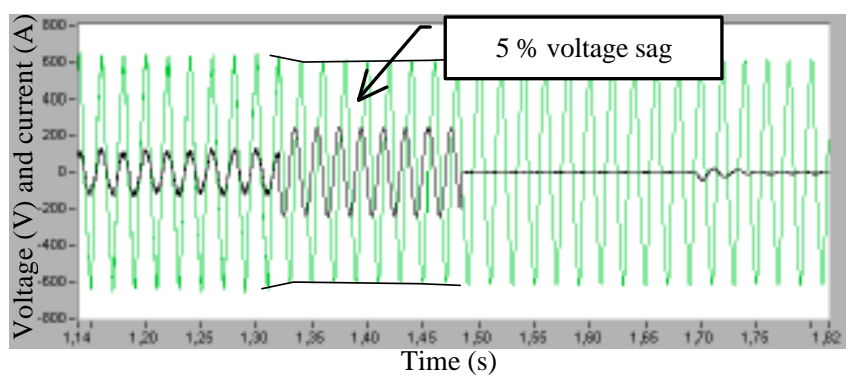

Fig. 5: Current (black) and voltage (grey/green) waveforms at DFIG during a disconnection. 
SQIG WT disconnects directly the generator opening the contactor (the soft-start thyristors are not used). In this turbine, the control disconnects the capacitors $1.6 \mathrm{~s}$ before the generator. In general, the generator usually operates as motor the last $0.5 \mathrm{~s}$ before disconnecting $(100 \mathrm{~kW}$ of peak consumption).

The time that the generator is connected without reactive compensation is short ( $80 \mathrm{~ms}$ in VRIG, $160 \mathrm{~ms}$ in DFIG and $1.5 \mathrm{~s}$ in SQIG). This fact seems to depend on the control and the security margin, not on the generation technology.

\section{A.3 Switching of capacitor banks}

Voltage and current distortion can be easily viewed in low voltage at turbine starting or stopping. The connection of a capacitor bank is shown in Fig. 6, where waveforms are three phase-to-neutral voltage waveforms and the smaller waveform is current of $\mathrm{R}$ phase in amperes. The connection causes transitory $9^{\text {th }}$ order harmonics in current, which are damped in one grid cycle, approximately. The current harmonics also causes distortion in voltage, as it can be seen in the same figure.

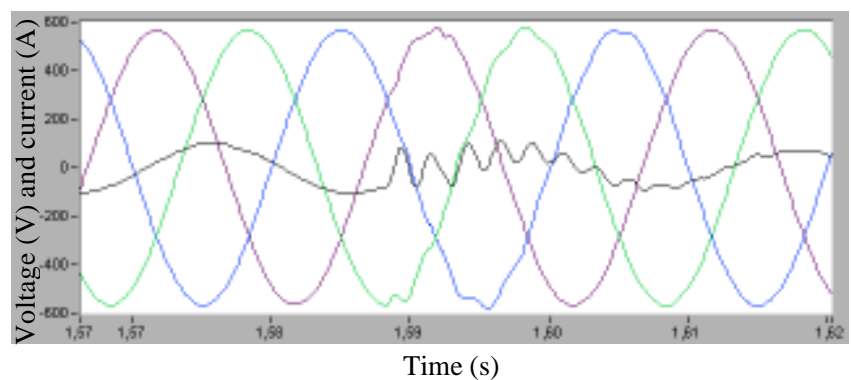

Fig. 6: Connection of a capacitor bank, measured at VRIG (small waveform is total current of one phase and the other three are phase-to-neutral voltage).

The behaviour during the connection of a capacitor is quite dependent on the parameters of the inrush inductance of the bank and the equivalent impedance at the WT. For example, in one SQIG the connection of capacitors only introduces significant distortion at the connection instant, as it can be seen in Fig. 7.

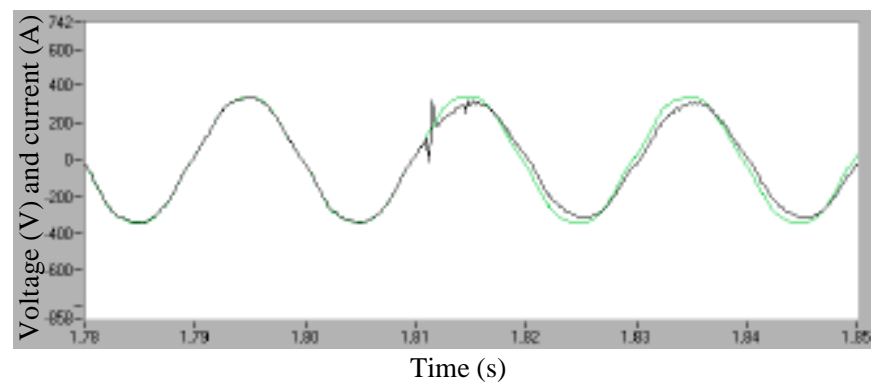

Fig. 7: Connection of a capacitor bank, measured at SQIG (green line is the generator current and black line is total current).

\section{A.4 Process of connection}

Fig. 8 shows RMS values of current in a connection of a VRIG, Fig. 9 shows RMS values of phase-to-neutral voltage and Fig. 10 shows power, generator slip and wind speed. Current at connection is very reactive and causes $2.5 \%$ of voltage drop in WT although it cannot be seen in the substation. After 0.6 seconds, the soft start finishes and thyristors are short-circuited. After $2 \mathrm{~s}$, the first capacitor (62.5 kVAr) is connected. Then the second one $(62.5 \mathrm{kVAr})$, third one (50 kVAr) and forth one (50 kVAr) with a lapse of $1 \mathrm{~s}$. After $6.6 \mathrm{~s}$, the whole capacitor bank is connected and voltage in WT is restored.

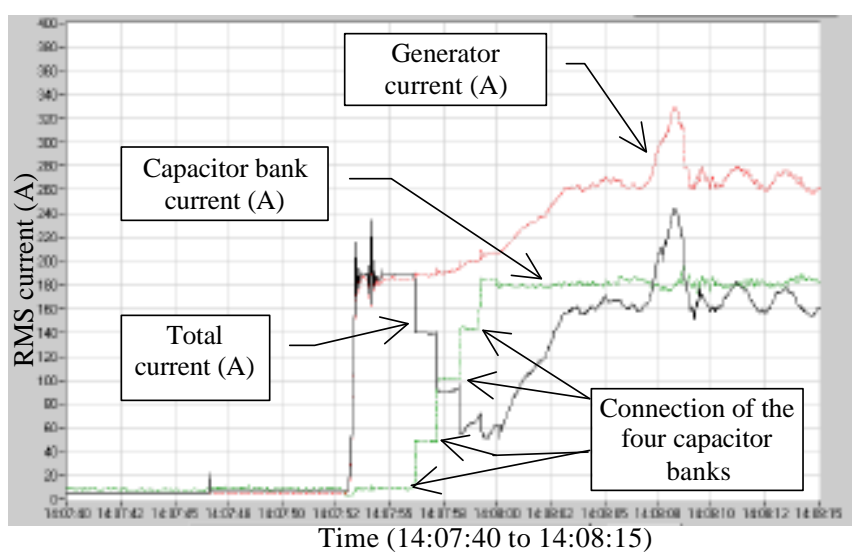

Fig. 8: Phase-to-neutral voltage, current and power during the connection of VRIG.

Due to the initial reactive current, the voltage drops $2.5 \%$ during the connection and afterwards, it is restored to previous values (see Fig. 9).

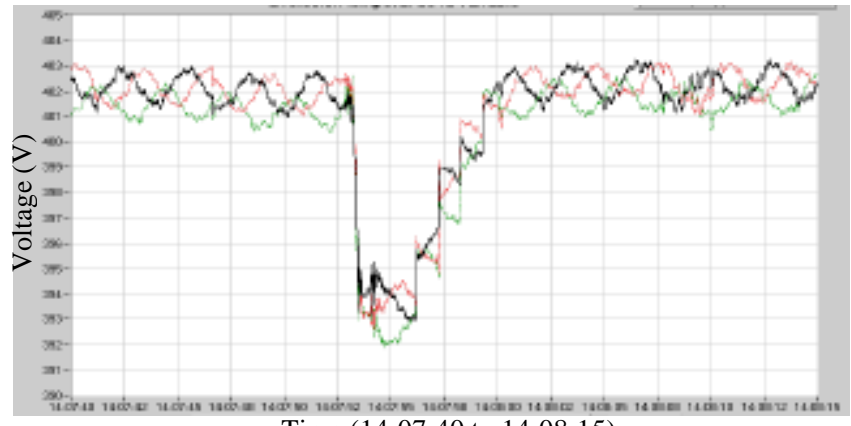

Time (14:07:40 to $14: 08: 15)$

Fig. 9: Detail of voltage sag at thyristor soft start in VRIG that lasts until all four capacitors are connected.

The pitch angle is adjusted at connection so the blades are operating with lower tip speed ratio $\lambda$ than the maximum performance point, in order to control generator speed during connection. If wind decreases, tip speed ratio $\lambda$ increases and the power coefficient $\mathrm{C}_{\mathrm{p}}$ increases. Therefore, the operating point is more stable since decreases of wind speed are partially compensated by the increase of the performance of the blade.

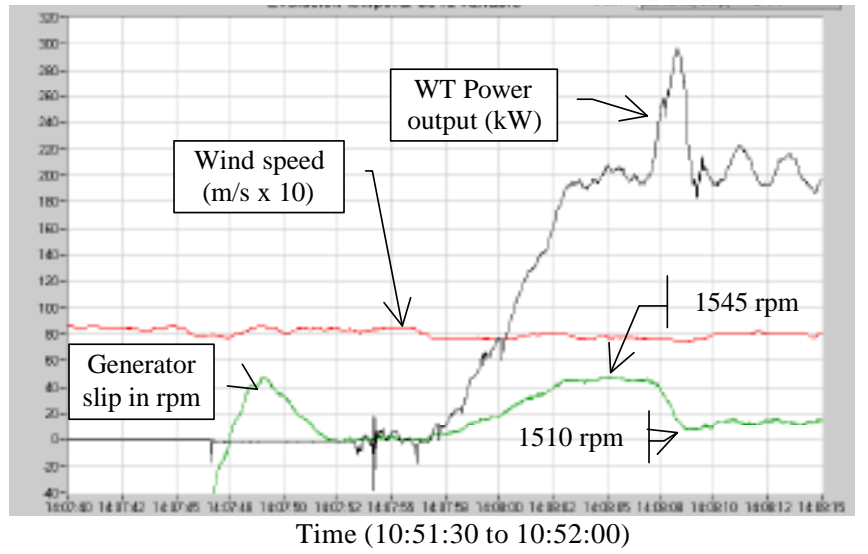

Fig. 10: Power, generator speed and wind speed during a connection of a VRIG. 
The role of the pitch angle control can be seen clearly in Fig. 11. At first, the generator tends to increase speed and pitch increases from $3^{\circ}$ to $16^{\circ}$. This way the generator slows down from $1375 \mathrm{rpm}$ to $1262 \mathrm{rpm}$. At this point, the speed is optimum to initiate thyristor soft-start. Just after the generator is connected, the pitch decreases up to reaching the maximum power output of the turbine (pitch near $0^{\circ}$ ). Due to the design of the analyzed DFIG, it operates in three modes depending on the generator speed: sub-synchronous (1235 $\pm 15 \mathrm{rpm})$, synchronous (1250-1540 rpm) and hypersynchronous $(1580 \pm 40 \mathrm{rpm})$. The steep changes of power in Fig. 11 corresponds to the changes in the operating mode.

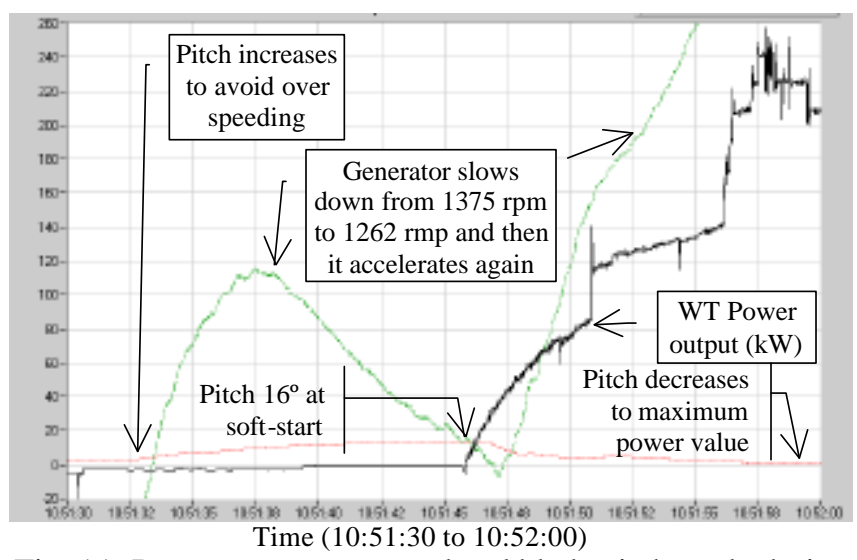

Fig. 11: Power, generator speed and blade pitch angle during a connection of a DFIG.

\section{A.5 Electronic power converter}

The distortion caused by the rotor converter can be noticed clearly in Fig. 12, when it starts to operate. Phase-to-neutral voltage presents also $3^{\text {rd }}$ harmonic, probably due to $3^{\text {rd }}$ harmonic current by neutral conductor. The transformer installed inside the WT has Dy11 connection to block symmetric harmonics of $3 \cdot \mathrm{N}^{\text {th }}$ order.

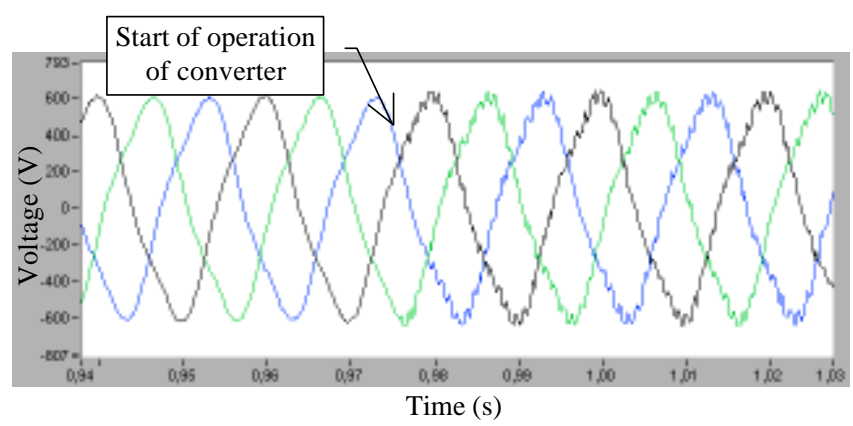

Fig. 12: Connection of the rotor converter of a DFIG.

High frequency inter-harmonics are largely filtered by turbine and substation transformers. Those inter-harmonics originated by the switching of IGBT at about $8 \mathrm{kHz}$ did not appear at the substation in a DFIG farm. Therefore, those harmonics only bothers equipment inside the WT (provoking noise, induced currents and incorrect operation of circuits not shielded from interferences), but they are not transmitted outside.

\section{A.6 Influence of switching events in the farm substation}

The effect of switching operations in farm substations is notably decreased due to higher short-circuit power, use of electronics and non-simultaneous connection or disconnec- tion. Fig. 13 shows current at substation output in a DFIG wind farm during the gradual connection of turbines after a stop command. Current increases gradually and some glitches are only noticeable at substation due to inrush currents.

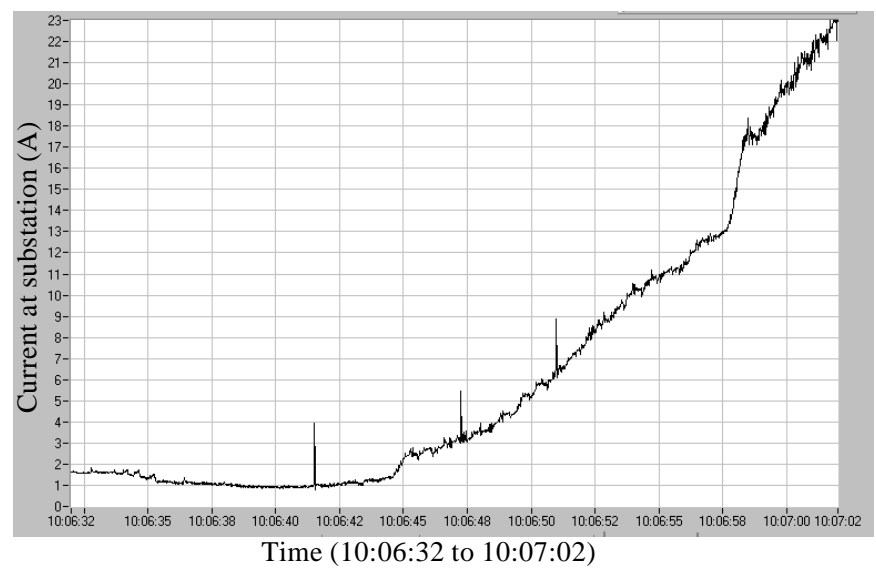

Fig. 13: Current during the gradual connection of turbines of a DFIG wind farm after a stop of the farm.

The disconnection of the WT shows a similar pattern. The turbines of the wind farm receive the stop command and the $16 \mathrm{WT}$ stop in less than $30 \mathrm{~s}$. The steps in figure 14 represent the disconnection of a turbine. Even though the command to stop was send to all the turbines simultaneously, the turbines stopped gradually and only once two turbines coincided disconnecting at the same time. However, the disconnection of all the turbines simultaneously can happen if any substation protection of the substation gets fired.

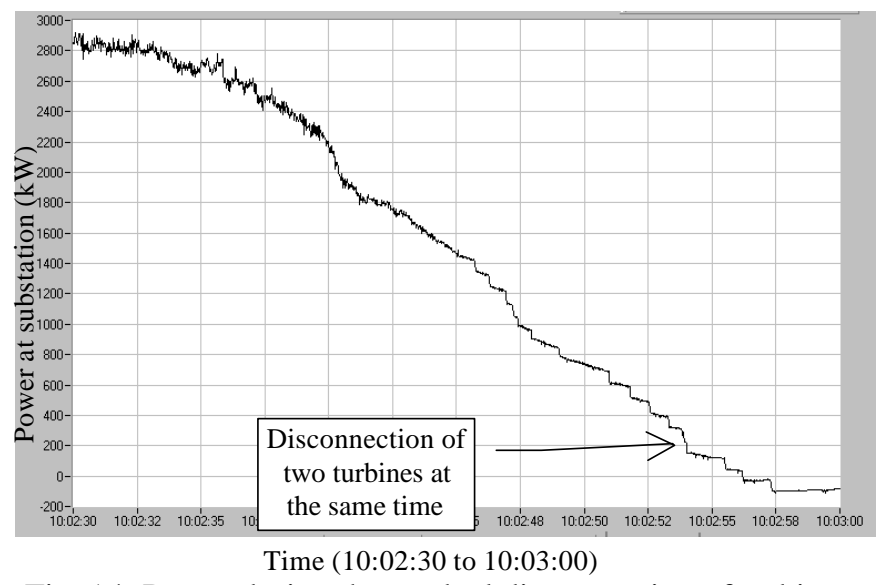

Fig. 14: Power during the gradual disconnection of turbines of a DFIG wind farm just after a stop command.

Disconnection of a single turbine at VRIG wind farm substation is shown in Fig. 15, where the effect is much lower since the wind farm has $22 \mathrm{WT}$. The disconnection is visible in wind farm current because there was only a turbine generating (the remaining current is very small, about $3 \%$ of rated current and it is mainly due to magnetizing current of WT transformers and stand-by loads).

However, a disconnection is unusually detected at current of a substation. The best way to detect switching events is to monitorize changes in lag angle between voltage and current because at connection or disconnection there is a peak of very inductive current. Measurements have shown that simultaneous switching of more than two WT is unlikely to happen in the farm analyzed. 


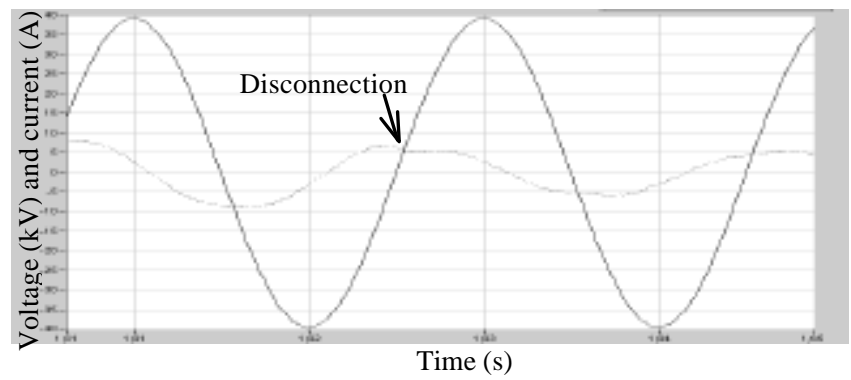

Fig. 15: Disconnection of one VRIG, measured at $66 \mathrm{kV}$ substation line.

\section{B. POWER FLUCTUATIONS}

In [9], three models of asynchronous machine were used to represent a wind turbine connected to an electrical grid (the equivalent dynamic one-phase time domain model, the equivalent dynamic one-phase frequency domain model and the stationary model). The new frequency domain model is based on the dynamic one-phase model and on the application of Fourier analysis.

The amplitude of the current oscillations in a generator will depend on the grid parameters, on the generator parameters and on the voltage level. The fluctuations of the current are not exactly sinusoidal, so that it can appear components with frequency multiple of the mechanical oscillations.

Feijoo proposes the representation of the machine respect to the electrical system, as a sum of several sources of current with different frequencies, which will produce a voltage oscillation at the connection point.

There is also some effort focused on the modelling of asynchronous generators connected by means of electronic converters $[10,11,12,13]$. These papers generally use directly the generalized machine model with the direct and transversal axes.

In a wind turbine the mechanical power presents fluctuations with a frequency corresponding to the blade passing the tower and its multiples. These mechanical power fluctuations are difficult to determine; however the generated electrical power and the current injected by the generator can be measured using proper equipment. From these measurements, the turbine could be modelled as a sum of sources of current with the different frequencies.

\section{B.1 Experimental data}

Power at WT shows fluctuations in power corresponding to blade passing the tower (approximately 1,54 Hz) and its sub-multiples, half $(0,77 \mathrm{~Hz})$ and one $(0,51 \mathrm{~Hz})$ rotor revolution. Fig. 16 and Fig. 17 show the averaged spectrum of the generated power at DFIG substation [14,15,16]. Nevertheless, mean fluctuation is small compared to the nominal power of the farm due to partial cancellation of oscillation.

The mean values (average of module) of oscillation showed in Fig. 17 for a wind farm of 11,2 MW at 8-10 m/s are $1122 \mathrm{~W}$ at $1,54 \mathrm{~Hz}, 501 \mathrm{~W}$ at $0,74 \mathrm{~Hz}$ and $1412 \mathrm{~W}$ at 0,5 $\mathrm{Hz}$. There are fluctuations of small value of 22,86, 24,2 and $24,8 \mathrm{~Hz}$. These frequencies have not appeared in other farms and some type of resonance or fluctuating loads can originate them.

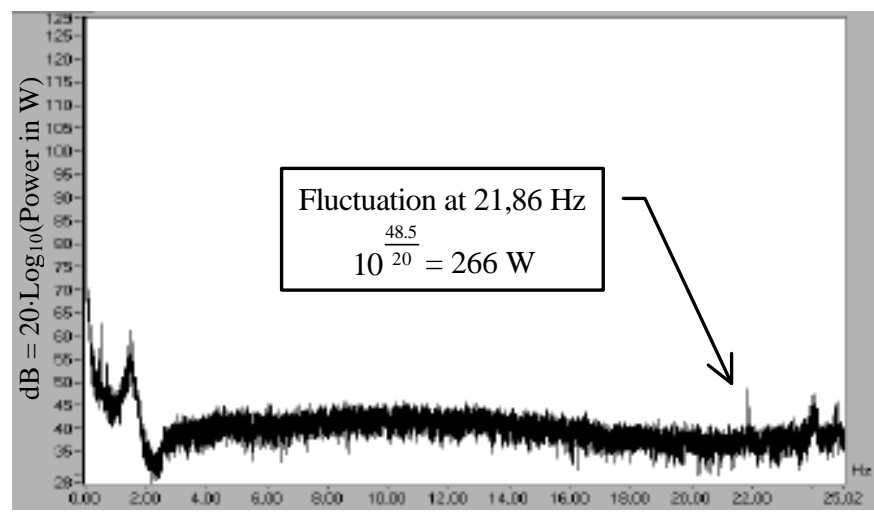

Fig. 16: PSD (module averaged) of generated power at DFIG substation with wind speed around $8-10 \mathrm{~m} / \mathrm{s}$.

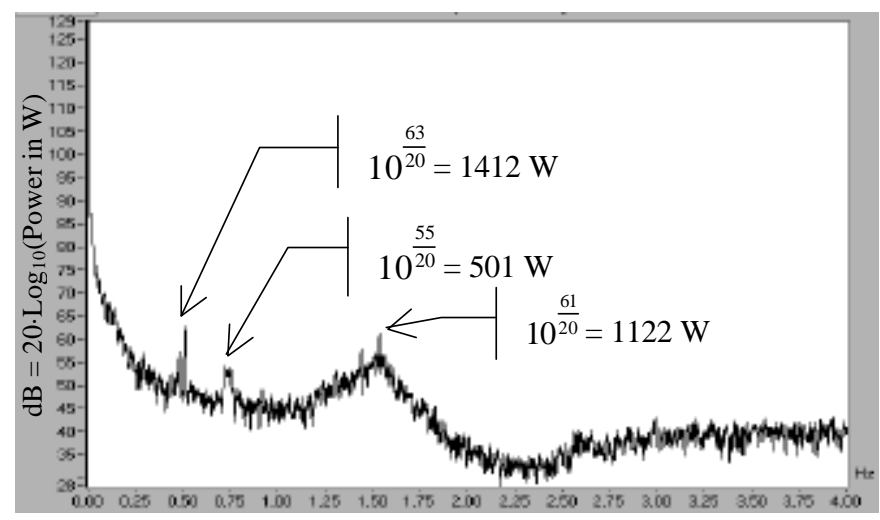

Fig. 17: Detail of previous figure (blade passing frequencies).

PSD of voltage decreases quickly, so these power fluctuations hardly affect voltage and the flicker emission is low [17].

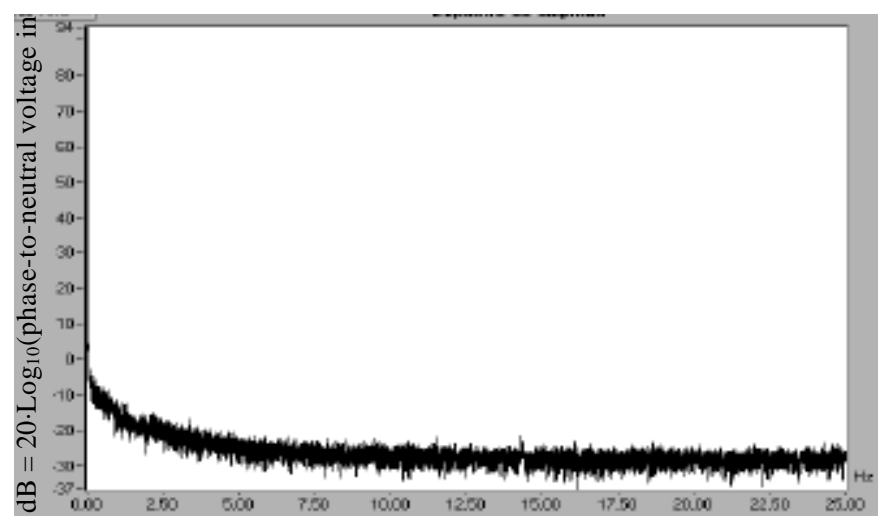

Fig. 18: PSD of voltage at DFIG substation with wind speed around $8-10 \mathrm{~m} / \mathrm{s}$.

Fig. 19 shows the PSD of a substation with VRIG. PSD of VRIG is similar to DFIG, but VRIG does not contain oscillations near $22-24 \mathrm{~Hz}$ and the oscillation of $0,77 \mathrm{~Hz}$ does not exist either. The fluctuation at $0,5 \mathrm{~Hz}$ has a smaller value (about $55 \mathrm{~dB}$ or $562 \mathrm{~W}$ ) than in VRIG.

However, the content of frequencies below $0,5 \mathrm{~Hz}$ has increased (about $65 \mathrm{~dB}$ or $1778 \mathrm{~W}$ ). The generator speed has narrower limits in VRIG and therefore, the stored energy in the inertia is smaller. The frequencies of blade passing in front of the tower (around 1,5 Hz) and its sub-multiples can vary due to different rotor speed. 


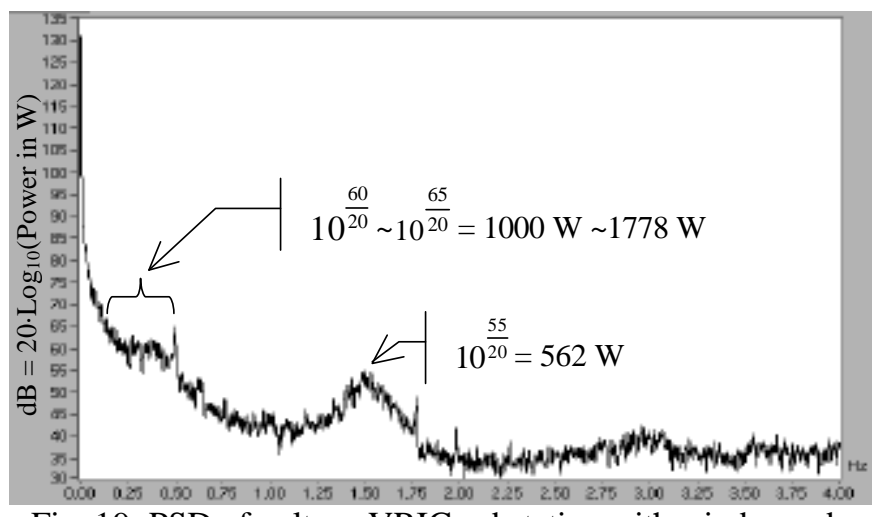

Fig. 19: PSD of voltage VRIG substation with wind speed around $8-10 \mathrm{~m} / \mathrm{s}$.

\section{B.2 Spectrogram}

This section is focused on the oscillations between 0.1 and $25 \mathrm{~Hz}$, which are the most influential in the flicker level. This range covers the fluctuations due to the blade passing the tower and its frequency multiples, the fast wind gusts and the possible resonance in the machine (with pure mechanical or aerodynamical origin).

The upper frequency limit is set because the RMS power values for every cycle or semi cycle are taken as input data, and the sample rate is therefore 50 or $100 \mathrm{~Hz}$. In order to carry out a study of the high frequency fluctuations, instantaneous power should be taken as an input data. The main disadvantage of using the instantaneous power is that the CPU time and the memory requirements increase notably.

The standard IEC 61400-21 establishes a procedure to calculate the flicker produced by a wind turbine in power grid, from real data. This standard takes into account fast fluctuations, being the most important those with a frequency from 6 to $25 \mathrm{~Hz}$.

It can also appear faster fluctuations than those showed in this document, mainly caused by imbalance in the rotating parts (generator and turbine rotor, gear and elastic constants of the shaft). During the connection and disconnection of the generator, the system is in a transient state showing fast fluctuations. This phenomenon has been directly appreciated in the waveforms.

The analysis of fluctuations between 0.1 and $25 \mathrm{~Hz}$ has been performed using the spectrogram of the active and reactive power variables. This fact lets study the variation of spectrum with time. Whether we only paid attention to the PSD module average, we could lose some sporadic fluctuations.

Apart from the SFFT, other methods have been tested for the calculation of the spectrogram, as the Wigner-Ville distribution (WVD) and the S-method (SM) [18]. As the analyzed signals present several frequency components, the SFFT method is the most reliable and the amplitudes of the fluctuations are not affected by cross-term interferences. The main disadvantage of SFFT is that it gives worse resolutions than the other methods, in case they can be applied.

The WVD is the best way to observe the frequency of fast fluctuations, as the frequency resolution is higher. The main drawback of this method is that the fluctuations are overestimated (i.e. for a fixed frequency, the measured fluctuation is higher than the real one). Therefore, the WVD values are only comparable with those of other different frequencies. Owing to lack of memory, the original signal has been divided in 8192 samples with a $75 \%$ overlapping, in order to apply the WVD and then discarding the overlapping edges.

The S-method, as it has been performed, presents noise problems with the analyzed signals, being discarded. In order to apply it to these signals, the window should include every auto-term without presenting cross-terms.

In a time-frequency SFFT analysis of a WT, shown in Fig. 20 , we could see that maximum fluctuations occur at connexion of WT and in second place, at connexion of capacitor banks (steep changes generate a broad spectrum of frequential components). [19, 20].

To calculate the spectrogram (evolution of spectral power density with time) it has been used the SFFT, with a Hanning window of 128,256 or 512 samples, relative to an approximate time of $2.5,5$ or $10 \mathrm{~s}$ and a $50 \%$ overlapping. The 256 samples window provides enough frequency resolution for our aims and has a fast enough response in the time domain. The $50 \%$ overlapping has been used to increase the time axis resolution and to improve the estimation of the PSD module average, which has been obtained with the mean value of the spectrogram. Hanning window has been used because of its good properties for general purposes (other windows were tested, but results were similar except for the rectangular one, where the result was clearly worse due to spectral leakage).

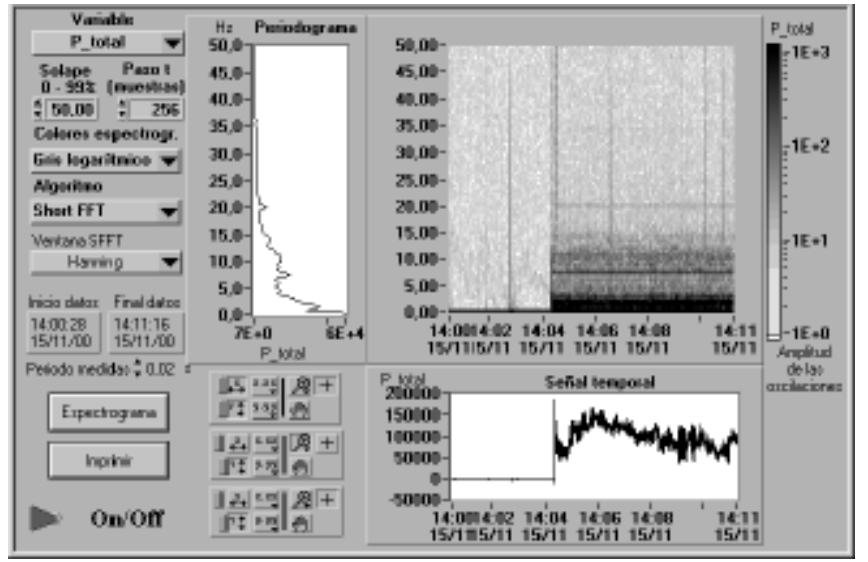

Fig. 20: Spectrogram of total power at SQIG of $750 \mathrm{~kW} \mathrm{WT}$ start-up.

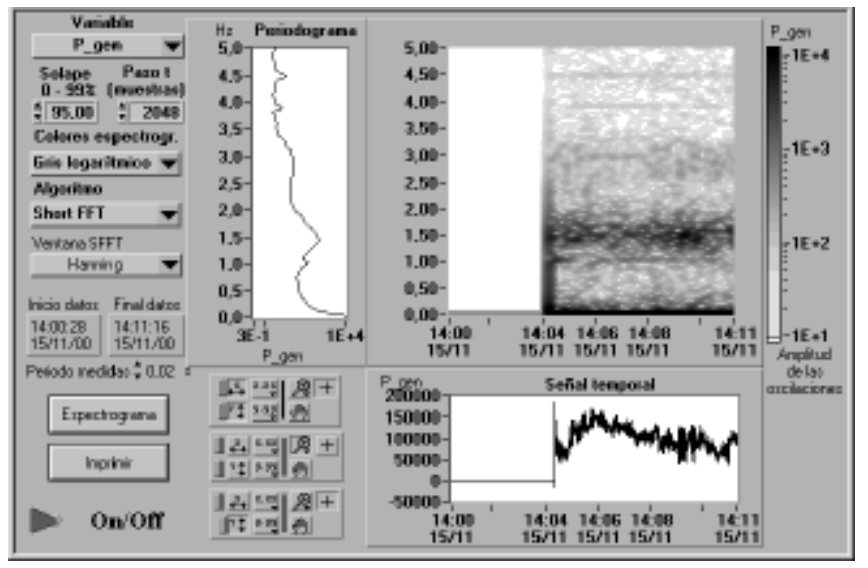

Fig. 21: Spectrogram of total power at SQIG of $750 \mathrm{~kW} \mathrm{WT}$ start-up. Detail of tower shadow frequencies. 


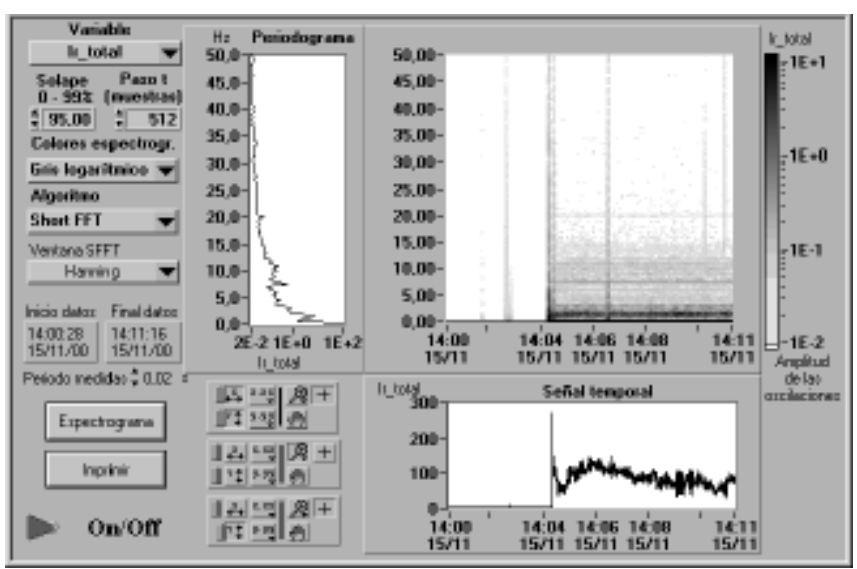

Fig. 22: Spectrogram of total current at SQIG of $750 \mathrm{~kW}$ WT start-up.

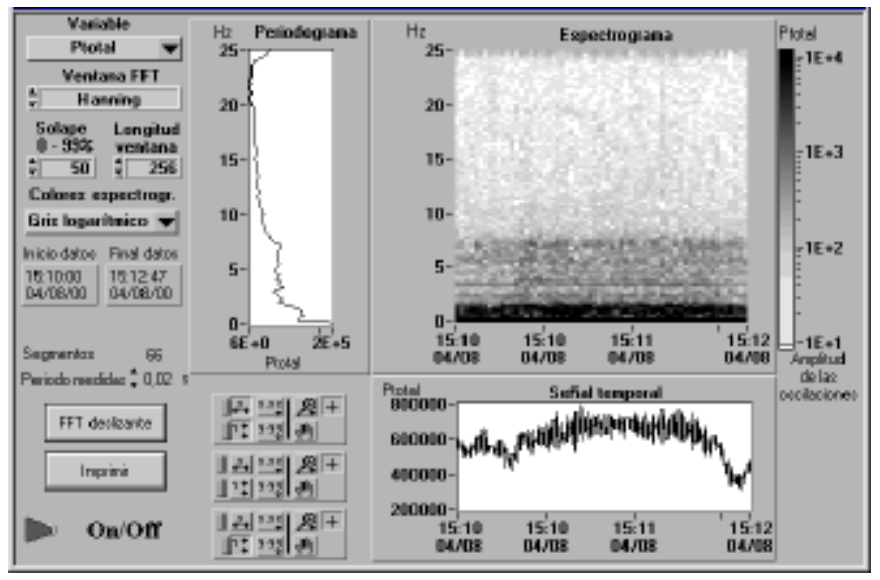

Fig. 23: Spectrogram of output power at SQIG of $750 \mathrm{~kW}$ during normal operation.

\section{CONCLUSIONS}

The performance of SQIG, VRIG and DFIG has been compared. SQIG with fixed blades has a simpler control, but it presents higher inrush current and fluctuations. However, SQIG can be improved if the connection of capacitor banks is speeded up. The softest connections are achieved in DFIG.

The measurement system used was proved very useful and its flexibility has made possible to make some dynamic studies, which require a fast and synchronised measure.

The high level inter-harmonics of DFIG only affect significantly devices inside the WT. These inter-harmonics are not in phase among the turbines and they are largely blocked by inductances and they did not appear at substation.

Fluctuations at power and current output of studied substations are low, fluctuations are low at voltage and they do not originate flicker levels of significance, at least at the farms analyzed.

Joint time-frequency analysis has been applied to the power generated by WT and confirmed that fluctuations are stronger at connection and at other transients. The fluctuations reach a steady value at normal operation and no special resonance conditions have been found up to now.

\section{REFERENCES}

[1] W. Frost, C. Aspliden. Wind Turbine Technology. Chapter 8. ASME Press. Editor D. A. Sphera.
[2] R. Klosse, F. Santjer y G. Gerdes, Flickererzeugung durch Windenergieanlagen. DEWI Magazin, no 10, pp. 30-38, Feb. 1997.

[3] L. L. Freris, Wind Energy Conversion Systems, Prentice Hall, 1990.

[4] Kaimal, J. C., J. E. Gaynor and D. E. Wolfe, 1981, Gust-Rise Statistics of Wind Speed and Direction for Two Strong Mountain Downslope Wind Cases for Wind Turbines, DOE/ET/23115-80-1, Boulder, Colorado: Environmental Research Laboratories.

[5] S. Heier. Grid integration of wind energy conversion system. John Wiley \& Sons Ltd. 1998 (traducido del alemán, Windkraftanlagen im Netzbetrib, 2. überarbeitete und erweiterte Auflage. B.G. Teubner Stuttgart 1996).

[6] R. Criado, J. Soto, J.M. Rodríguez, et al. "Analysis and control strategies of wind energy in the Spanish power system" International Conference on Large High Voltage Electric Systems, CIGRÉ. 2000.

[7] T. S. Nielsen, A. Joensen, H. Madsen, L. Landberg, G. Giebel. A New Reference for Wind Power Forecasting. Wind Energy, 1, 25-45 Septiembre 1998.

[8] T. Sfetsos, A. H. Coonick. Time Series Forecasting of Mean Hourly Wind Speed and Power. VI Jornadas Hispano-Lusas. Lisboa 1999.

[9] A. E. Feijóo Lorenzo. Tesis Doctoral. Influencia de los parques eólicos en la seguridad estacionaria y calidad de onda de Redes eléctricas de gran dimensión. E.T.S.E.I.M. Vigo 2000.

[10] P. Vas. Vector Control of AC Machines. Oxford University Press, New York 1990.

[11] S. Wade, M.W. Dunningan, D.W. Williams. Modeling and Simulation of Induction Machine Vector Control with Rotor Resistance Identification. IEEE Trans. On Power Electronics, Mayo 1997.

[12] G. Tapia, A. Tapia, J.J. Molina, J.R. Saenz. Simulación y Control de Parques Eólicos con Generadores de Inducción Doblemente Alimentados. X Reunión de Grupos de Investigación en Ingeniería Eléctrica. Santander 2000.

[13] Peña R.S., Clare J.C., Asher G.M., Vector control of a variable speed dobly-fed induction machine for wind generation systems. EPE Journal, vol. 6, no. 3-4, pp. 60-67, 1996.

[14] N. Visbøll, A. L. Pinegin, T. Fischer, J. Bugge. "Analysis of Advantages of the Double Supply Machine With Variable Rotation Speed Application in Wind Energy Converters". DEWI Magazin Nr. 11, August 1997. Available: http://www.dewi.de/ dewi/magazin/11/08.pdf

[15] A. Feijoo, J. Cidras. "Analysis of mechanical power fluctuations in asynchronous WECS". IEEE Transactions on Energy Conversion, Vol. 14, No. 3, pp. 284-291. Sept. 1999.

[16] E. Bossanyi, Z. Saad-Saoud and N. Jenkins. Prediction of Flicker Produced by Wind Turbines. Wind Energy 1, pp 3551. 1998.

[17] H. Amarís, J. Usaola. Evaluación en el dominio de la frecuencia de las fluctuaciones de tensión producidas por los generadores eólicos. V Jornadas Hispano-Lusas de Ingeniería Eléctrica. 1997.

[18] Igor Djuroic, Ljbisa Stankovic. A Virtual Instrument for Time-Frequency Analysys. IEEE Trans. Instrumentation and Measurement, vol. 48, no. 6, December, 1999.

[19] Igor Djurovic, Ljubisa Stankovic. "A Virtual Instrument for Time-Frequency Analysis" IEEE Trans. on Instr. Meas. Vol. 48, No. 6, pp. 1086-1092. 1999.

[20] Tomasz P. Zielinski. "Joint Time-Frequency Resolution of Signal Analysis Using Gabor Transform" IEEE Trans. on Instr. Meas. Vol. 50, No. 5, pp. 1436-1444. 2001. 